\title{
One-third of doctors completing specialist training in diabetes fail to secure a substantive consultant post: Young Diabetologists'
} Forum survey 2010

\author{
Kelly Cheer, Jyothis T George, Paul Grant, Roselle Herring, Rahat A Maitland, Milan Piya, Hermione C Price, \\ Emma G Wilmot and Rowan Hillson
}

\begin{abstract}
Reports have highlighted a shortage of consultant diabetologist posts in the UK. The number of doctors completing specialist training in diabetes has increased in recent years, but little is known about their employment after they receive their certificate of completion of training. An online survey was sent to all doctors who completed specialist diabetes training from January 2008 to September 2010. Of the 95 eligible respondents, 69 (73\%) completed the survey (61\% men; median age 36 years). Forty-three (62\%) respondents secured substantive NHS consultant posts, and of those who gave their job breakdown, 48/51 (94\%) were contributing to specialist diabetes care. Five (7\%) respondents held substantive academic positions, while 11 (16\%) were locum consultants. Seven (9\%) respondents worked abroad, with half of these attributing their emigration to lack of opportunities in the UK. When asked about alternative choices, $39 \%$ of respondents were likely to seek 'general physician' roles, which equalled the number who would consider emigrating. Overall, only two-thirds of doctors who complete specialist training in diabetes secure substantive NHS consultant positions, which suggests a failure in workforce planning and a lack of expansion of the number of consultant posts despite progression of the diabetes epidemic.
\end{abstract}

Kelly Cheer, ${ }^{1}$ specialty trainee in diabetes and endocrinology; Jyothis T George, ${ }^{2}$ specialist registrar in diabetes and endocrinology, YDF chair 2012-13. Paul Grant, ${ }^{3}$ specialist registrar in diabetes and endocrinology; Roselle Herring, ${ }^{4}$ specialist registrar in diabetes and endocrinology; Rahat A Maitland, ${ }^{5}$ specialist registrar in diabetes and endocrinology; Milan Piya, ${ }^{6}$ specialist registrar; Hermione C Price, ${ }^{7}$ specialist registrar in diabetes and endocrinology and YDF Chair 201112; Emma G Wilmot, ${ }^{8}$ clinical research fellow in diabetes and YDF Chair 2010-11; Rowan Hillson, ${ }^{9}$ national clinical director for diabetes and consultant physician and diabetologist

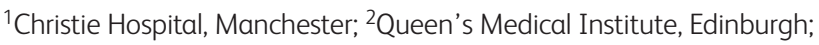
${ }^{3}$ King's College Hospital, London; "Worthing Hospital, Western Sussex; ${ }^{5}$ Guy's and St Thomas' NHS Foundation Trust, London; ${ }^{6}$ Centre for Endocrinology, Diabetes and Metabolism, University of Birmingham; ${ }^{7}$ Oxford Centre for Diabetes, Endocrinology \& Metabolism, Churchill Hospital, Oxford; ${ }^{8}$ Diabetes Research Department, Leicester Royal Infirmary; ${ }^{9}$ Hillingdon Hospital, London
}

KEY WORDS: consultant posts, diabetes and endocrinology, employment, workforce planning

\section{Introduction}

The prevalence of diabetes continues to increase dramatically, yet concern is mounting regarding the future employment opportunities for diabetes and endocrinology trainees in the UK. A number of evolving changes in delivery of the diabetes and endocrinology service are contributing to this concern. The National Diabetes Audit 2009-10 of 1.9 million people with diabetes ${ }^{1}$ reports considerable variability in the processes and outcomes of diabetes care. Many patients are not achieving National Institute for Health and Clinical Excellence (NICE) outcome targets: for example, only two-thirds of patients with type 2 diabetes and less than one-third of patients with type 1 disease achieved the $7.5 \%$ target level for glycosylated haemoglobin $\left(\mathrm{HbA}_{1 \mathrm{c}}\right)$. Organisational changes, combined with the ongoing financial crisis in the NHS, have led to a gradual reduction in the number of consultant diabetologist posts. ${ }^{2}$ In recent years, this has, in part, been compensated for by increasing numbers of acute medicine consultant posts that have been available to diabetologists. However, as more acute medicine trainees gain their certificate of completion of training (CCT), such posts may no longer be available to diabetes trainees, leading to a potential employment crisis in this specialty, despite the need for their expertise.

Trainees' concerns have recently been heightened by the results of the Royal College of Physicians (RCP) and Joint Royal Colleges of Physicians Training Board (JRCPTB)'s national survey of medical specialty CCT holders. ${ }^{3}$ This survey identified that $45 \%$ of diabetes and endocrinology CCT holders failed to secure a substantive consultant post in 2009, which increased to $63 \%$ in 2010, making diabetes and endocrinology the second worst medical specialty for securing employment after CCT in 2010 . However, this survey was limited by low response rates of $41 \%$ and $45 \%$ in 2009 and 2010, respectively. In 2011, 33\% of CCT holders in diabetes and endocrinology were unsuccessful in securing a substantive consultant post.

The Young Diabetologists' Forum (YDF) (www.youngdiabetologists.org) is the trainee wing of Diabetes UK and represents up to 800 specialist trainees and newly appointed consultants across the UK. The YDF, supported by Dr Rowan Hillson, 
national director of diabetes, identified the need to establish urgently the extent of consultant job shortages in order to assist planning to provide high-quality patient care and to support this highly skilled workforce.

\section{Methods}

The JRCPTB provided the YDF with the details of 95 diabetologists who obtained their CCT between January 2008 and March 2010. All trainees had achieved their CCT at least six months earlier. An online survey of 20 questions was developed and piloted by the project committee of 13 diabetes specialist registrars. The survey was emailed to all eligible participants. Responses were cross-referenced with email addresses held by training authorities to validate individual responses. When no response was received, the project committee made efforts to identify those diabetologists' location and work position.

\section{Results}

Of the 95 eligible respondents, 69 completed the full survey, giving a response rate of $73 \%$. Of the 69 respondents, $61 \%$ were male, and the median age at CCT was 36 years.

\section{Employment}

Forty-three (62\%) respondents held substantive NHS consultant positions, with $11(16 \%)$ in locum consultant positions and five $(7 \%)$ in research or senior lecturer posts (Fig 1). No doctor was unemployed or working as a specialty registrar. Time since receiving the CCT did not seem to affect whether respondents had secured a substantive consultant post, but those within 12 months of receiving their CCT were more likely to be working in a locum consultant post (5/19 (26.3\%) vs 5/50 (12\%)) (Fig 2).

\section{Type of consultant role secured}

Of the respondents in substantive consultant posts, 94\% (48/51) were contributing to specialist diabetes or endocrine care, usually in combination with an acute and/or general medicine com-

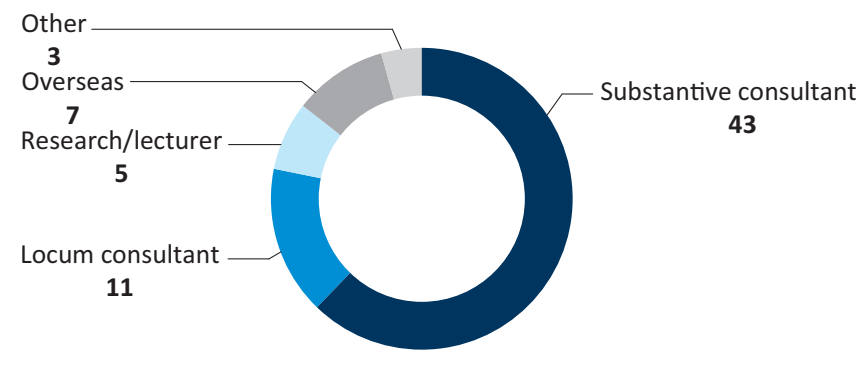

Fig 1. Current work situation of survey respondents (number of responses). a

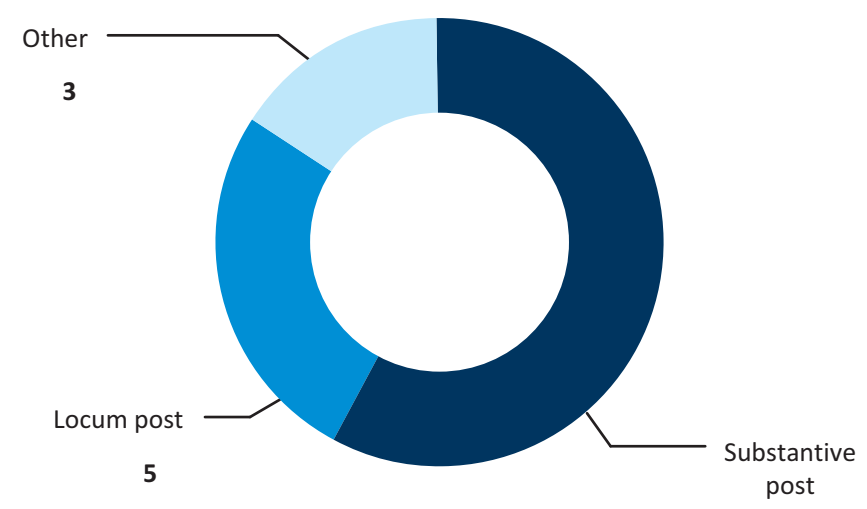

Within 12 months of CCT

11

b

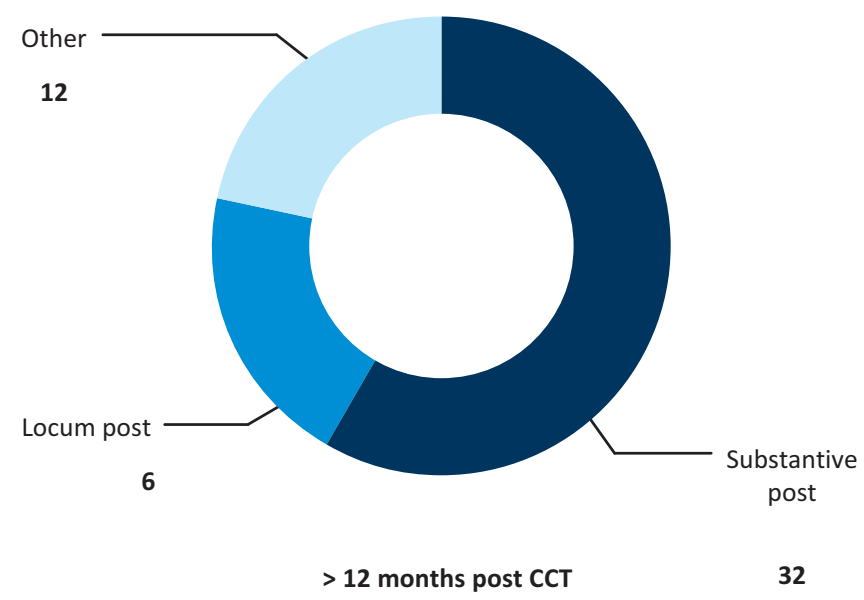

Fig 2. Type of consultant role secured (number of responses).

mitment (Fig 3). Only two (3\%) of the respondents were working in a purely acute medicine post with no specialist commitment. Acute medicine was defined as contributing to care on a medical admissions unit, whereas general internal medicine (GIM) involved patient care on other wards.

\section{Emigration}

Seven (9\%) respondents were working abroad after receiving their CCT, and half of these attributed their emigration to a lack of opportunities in the UK. Of those based in the UK, onequarter $(15 / 58,26 \%)$ had considered working overseas as a result of the shortage in consultant positions in the UK.

\section{Alternative career options}

When asked about alternative career choices if no NHS specialist consultant positions were available, 7/18 (39\%) doctors were likely to seek 'general physician' roles. Only $2 / 17$ who responded 


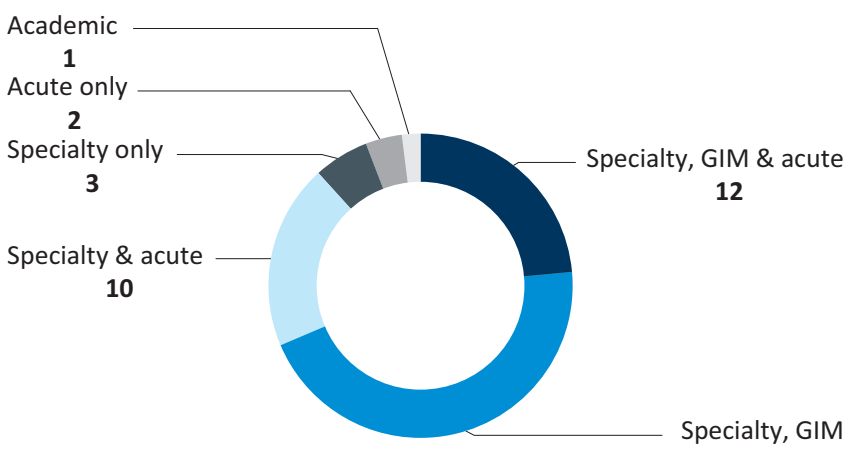

23

Fig 3. Employment according to time of CCT (number of responses).

(11.8\%) would consider retraining as a general practitioner or following a career outside of medicine.

\section{Work patterns}

When respondents were asked whether they would consider working less than full time, 19 (28\%) each replied 'yes' or 'would consider' and $26(38 \%)$ said that they would consider a job share.

\section{Factors influencing choice of employment}

Key factors influencing choice of consultant post were 'type of post' $(63 \%)$, location (30\%) and opportunity to do research (16\%). Other factors are shown in Table 1. Two respondents stated in the free text option that the quality of department and colleagues were most important.

\section{Preparedness for a consultant role}

Respondents were asked how well prepared they felt for a consultant post in each of diabetes, endocrinology, general medicine and acute medicine. The results showed that less than half of respondents felt 'very well' prepared for a consultant post in acute medicine, and yet a number of respondents were working in acute medicine posts (Table 2 ).

\begin{tabular}{|c|c|c|c|c|}
\hline Factor & $\begin{array}{c}\text { Very } \\
\text { important }\end{array}$ & Important & $\begin{array}{l}\text { Considered } \\
\text { in decision }\end{array}$ & $\begin{array}{l}\text { Did not } \\
\text { factor in } \\
\text { decision }\end{array}$ \\
\hline Type of post & 39 & 18 & 4 & 1 \\
\hline $\begin{array}{l}\text { Teaching vs } \\
\text { DGH }\end{array}$ & 6 & 24 & 24 & 8 \\
\hline Location & 21 & 31 & 9 & 2 \\
\hline On-call rota & 6 & 23 & 24 & 9 \\
\hline $\begin{array}{l}\text { Opportunity } \\
\text { for research }\end{array}$ & 10 & 17 & 18 & 18 \\
\hline
\end{tabular}

Table 2. Degree to which respondents felt prepared for consultant posts after receiving their certificate of completion of training (number of responses).

$\begin{array}{lcccc}\text { Specialty } & \text { Very well } & \text { Fair } & \text { Adequate } & \text { Poor } \\ \begin{array}{lccc}\text { Acute } \\ \text { medicine }\end{array} & 28 & 15 & 14 & 5 \\ \begin{array}{l}\text { Diabetes } \\ \text { Endocrinology }\end{array} & 44 & 16 & 3 & 0 \\ \text { General } & 36 & 12 & 6 & 0 \\ \text { medicine } & 19 & 4 & 2\end{array}$

\section{Employment issues for women}

Overall, 25 responses were from women: 15 (60\%) had secured substantive consultant posts and eight (32\%) had completed their training part time. Most women would consider working part time (13 replied 'yes', eight 'maybe' and four 'no') or would consider a job share (15 replied 'yes' and 10 'no').

\section{Non-responders}

A description of the current role was obtained for 16/26 nonresponders; 15 of these were still working in the UK and 11 of these were in consultant posts. The other was working in a substantive consultant diabetes and endocrinology post in Canada. For the 15/26 doctors still working in the UK, we were unable to determine whether their jobs were locum or substantive posts, and for the remaining 10/26 who did not respond to the survey, their ongoing work position was not determined.

\section{Discussion}

This YDF post-CCT survey complements previous work by the RCP and JRCPTB to investigate trainee career progression in the medical specialties. ${ }^{3}$ The results of our survey are not as alarming as the RCP/JRCPTB survey, which suggested that two-thirds of trainees in 2010 failed to obtain substantive employment, but the figures still give cause for concern. The government invests a substantial amount of money in the training of diabetes and endocrinology specialists, and we need to utilise their expertise to benefit our patients. It is encouraging to see that the overall rate of $62 \%$ of respondents securing a substantive NHS consultant post in our survey was higher than the $55.7 \%$ seen overall across the medical specialties in the RCP/JRCPTB survey in 2011.

There is an urgent need to address the current consultant job shortage in diabetes and endocrinology. Potential solutions include restricting trainee numbers - a step that has already been taken in some areas. The YDF survey has highlighted that many trainees would consider working part time or job sharing. This is a solution that the YDF is exploring further by considering a national register for trainees interested in job sharing in the UK. Trainees need curriculum vitae that are not only competitive in the current market but also diverse to ensure that they are 
equipped with the range of skills required to apply for posts in diabetes, endocrinology, acute medicine, general medicine, community diabetes and any combination of these. As diabetes care and service delivery continues to move closer to patients' homes, it is important that diabetologists have specialist skills that extend across the primary care-secondary care interface to ensure the delivery of high-quality care. ${ }^{4,5}$

The main strength of our survey was the high response rate of $73 \%$ compared to $45 \%$ for the RCP/JRCPTB survey. This comprehensive coverage helps to explain the difference in findings between the YDF and RCP/JRCPTB surveys. A further strength of our survey was the detailed information obtained on factors influencing choice of role and working pattern. However, the questionnaire did not ask participants to identify the proportion of their post that was made up by each of diabetes, endocrinology and general or acute medicine, or the overseas locations of those no longer working in the UK.

A potential employment crisis in diabetes and endocrinology is evolving. Steps must be taken to ensure that the specialist skills acquired by this cohort remain available to people with diabetes and that our patients continue to receive high-quality consultant-led care - a need that was clearly established by the National Diabetes Audit 2009-10. ${ }^{1}$ The YDF are actively engaging with the RCP, specialist advisory committee and specialist societies to identify potential solutions to this problem.

\section{References}

1 NHS Information Centre. National diabetes audit executive summary 2009-2010. Leeds: NHS Information Centre, 2011. www.ic.nhs.uk/ webfiles/Services/NCASP/Diabetes/200910\%20annual\%20report\%20 documents/National_Diabetes_Audit_Executive_ Summary_2009_2010.pdf [Accessed 22 March 2012].

2 Morrish N. Diabetes UK/RCP diabetes and endocrinology national manpower report 2010 consultant survey for the year ending 30th September 2009. www.diabetes.org.uk/upload/Reports/Manpower\%20report $\% 20$ 2010.pdf [Accessed 22 March 2012].

3 Goddard AF, Newbery N. Survey of medical CCT holders career progression 2009-11. London: RCP, 2011. www.rcplondon.ac.uk/sites/default/ files/survey-of-medical-cct-holders-career-progression-2009-11.pdf [Accessed 22 March 2012].

4 Department of Health. Delivering care closer to home: meeting the challenge. London: Stationery Office, 2008. www.dh.gov.uk/en/ Publicationsandstatistics/Publications/

PublicationsPolicyAndGuidance/DH-086052 [Accessed 22 March 2012].

5 Wilmot EG, George GT, Hawthorne G et al. The expansion of specialist community diabetes: the ABCD-CDC-YDF national community diabetes consultant survey 2010. Diabetic Med 2011;28(s1):145.

Address for correspondence: Dr Kelly Cheer, 34A Booths Hill Road, Lymm, Cheshire WA13 0DL.

Email: kellycheer@doctors.net.uk

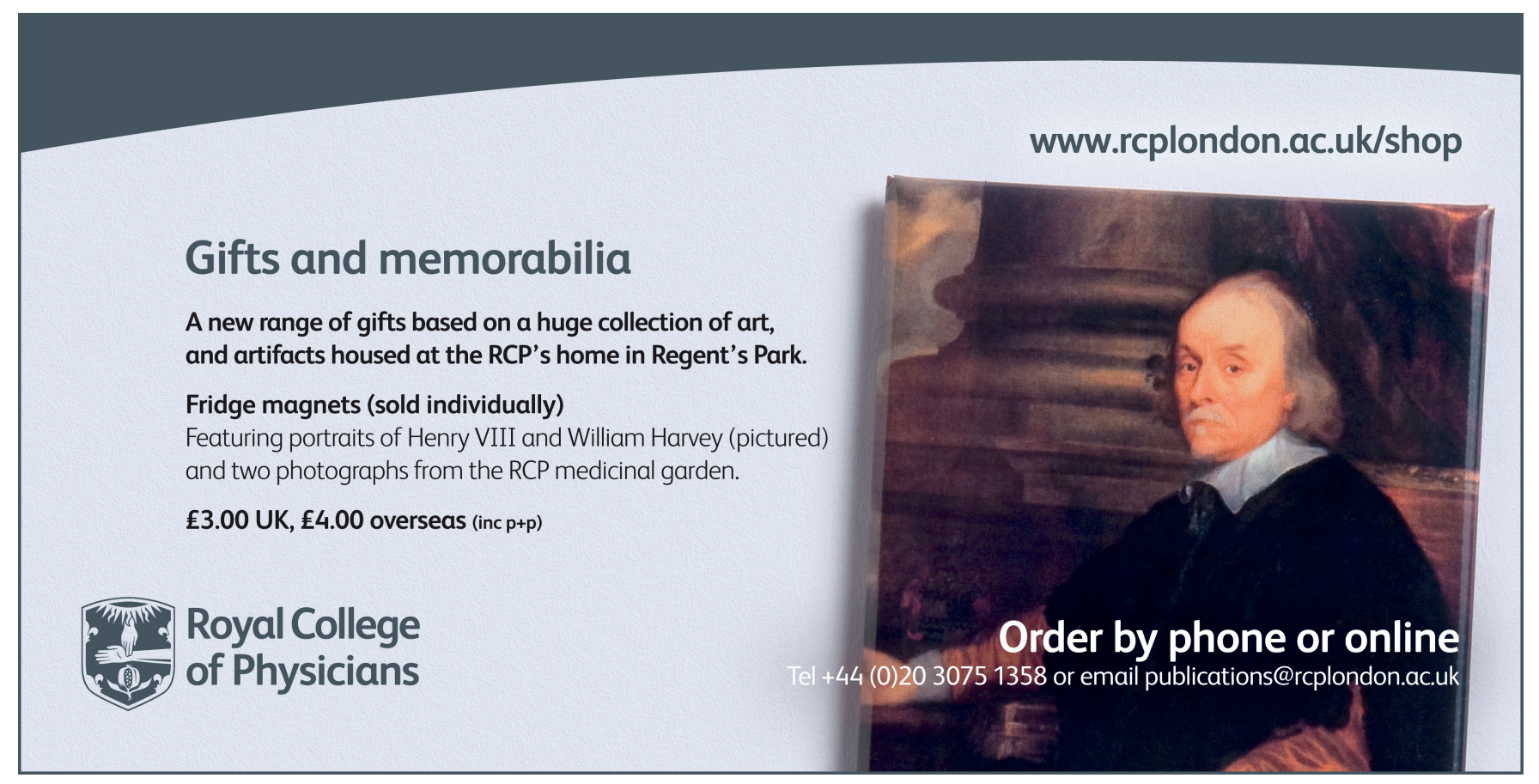

